\title{
LA NOVA POESIA GALLEGA
}

\section{Manuel Laurentino Suárez}

La poesía gallega tiene una larga y marcada tradición dentro de la lírica peninsular, a pesar de su escasa difusión fuera de su ámbito linguístico en la actualidad.

Hay que remontarse al comienzo de la poesía en la peninsula ibérica, para tratar de cerca con Galicia. Esta diminuta provincia española es de por si una de las que cuenta con más acusada personalidad. Alli se han desarrollado hechos transdentales entre los que resalta la creación de la leyenda del apóstol Santiago. Este mito llegó a producir grandes peregrinaciones medievales que como consecuencia colocaron a Galicia dentro del mapa europeo. En el llamado camino de santiago o Francés, se germinaron las leyendas épicas del siglo carolingio. No cabe duda que estas peregrinaciones fueron ls vías de penetración cultural más eficaces de la Europa medieval. Pero la historia de la provincia comenzó muchos siglos antes. En la época de Polibio, Posidonio y Estrabón, ya aparecía por escrito el nombro de la provincia, y también se hablaba del solar gallego. Hoy se sabe que existió una poesía española, cuyos restos se conservaron en las jarchas de las moaxajas árabes y hebreas de la alta edad media, estás son cántigas mozárabes que procedian de una lengua primitiva muy similar al gallego. Sin duda la lengua galaica tuvo un periodo de preponderancia sobre las que se fraguaban coetaneamente en el resto de la península ibérica. Ya lo afirmaron grandes hombres de letras como Marcelino Menéndez Pelayo al decir que el primer vehículo de la lengua peninsular fue la lengua gallega o portuguesa:

\footnotetext{
"El estudio de las caciones gallegas es, por una parte, suplemento necesario a la historia de la poesia provenzal, que en ellas revive o se prolonga; y es, por otro lado, la clave, poco menos que única, para la determinación de los origenes de la lírica castellana envueltos hasta ahora en tanta oscuridad y contradicción”. (1)
}

Este gran crítico español solo refunde el comentario que en el siglo XVI escribió el Marqués de Santillana en su tan conocida carta al ilustre Don Pedro, Condestable de Portugal:

"É despues fallaron esta arte, que mayor se llama, é el arte comun, creo en los reinos de Galicia é Portugal, donde non es de dubdar que el ejercicio de estas ciencias más que en ningunas otras regiones ni provincias de la España se acostumbró en tanto grado, que non há mucho tiempo cualesquier decidores 
é trovadores destas parte, agoran fuesen castella-

nos, andaluces ó de la Extramdura, todas sus obras componian en lengua gallega ó portuguesa». (2)

Cuando la lengua castellana empezada a dar sus primeiros gemidos, Galicia ya cantaba en la suya a través de esas preciosas joyas de la literatura universal que se llaman concioneiros de la Vaticana, de Ajuda, y de Colocci Brancutti.

Así pues, para escribir de la nueva poesía gallega se debe tomar un punto de partida. La guerra civil española servirá como en otras muchas ocasiones como fecha clave. En este trabajo se mencionarán poetas que se han dado a conocer o que han surgido después de la fratricida contienda.

Seria myi dificil tratar de escoger al primer gran poeta gallego de la porguerra, pero la crítica en general tienda a señalar a Manuel Cuña Novas como el escritor que más influye en la poesía gallega de los años cuarenta y cinquenta. Cuña Novas en Pontevedra en 1926, y publicó un solo libro en 1952, Fabuleiro Novo. Su producción literaria ataca a la actitud derrotista, de culpabilidad, de inferioridad y pessimista de sus compatriotas. La palabra en este poeta, más que una mera función estética, tiene un profundo significado metafísico. Otro contemporáneo de Cuña Novas fue Don Eugenio Novoneyra, el cual nación en Parada de Moreda, Lugo, en el año 1930. Su obra fundamental es: Os Eidos, donde el escritor crea una nueva dimensión profunda y enternecedora del sentimiento de la tierruca. Se ven en él los antecedentes aislados de otros poetas gallegos que invocaron a la madre tierra como elemento de inspiración, donde se anulan los sentimientos y las emociones personales a favor de lo cósmico. Otro gallego que merce mención es Manuel Maria Fernandéz Teixeiro, nacido en Outeiro del Rey (Lugo) en 1930. Posiblemente uno de los más fecundos del grupo. El poeta ve su obra como algo mágico e inexplicable, algo que brota del más allá, de una dimensión desconocida e incomprensible. En sus versos no dice cómo el mundo es en realidad, sino cómo debe ser.

Alexandre Cribeiro nació en al año 1936 en Pontevedra. Ha obtenido numerosos premios por su excelente poesia, y varios centros gallegos a través del mundo le han donado honores a causa de su limitada pero bella producción lírica. Cribeiro ve todo lo que le circunda como poesía, pero principalmente se preocupa por dos temáticas: la amorosa y la política, asi pues casi toda su producción gira alrededor de estos dos temas. Su poesía amorosa es de raiz intimista, mientras que la politica tiende a tener una profunda preocupación social, el injerto de estas dos temáticas hacen del poeta un hombre complejo y a veces difícil de comprender. Posiblemente su mejor libro es Indo pra mais perto, el cual permanece aun inédito. Junto a Cribeiro se debe mencionar a un escritor que nació en Orense en el año 1938, Xosé Luis Méndez Ferriń. Su gran importancia reside en haber sido uno de los principales fundadores de la colección Brais Pinto, que por mucho tiempo servió de elemento propulsor a las actividades de los jóvenes poetas gallegos que residian en la capital española. Su único libro de poemas, Voces no neboa, surgió por 1957. Más que poeta, es narrador lírico. Su poesía llega a ser muy tensa, y a la vez goza de gran plasticidad.

Otro escritor que debe estudarse es Farruco Sesto, este poeta que emigró de Galicia cuando era un adolescente, supo mantenerse fiel a la tradición de su solar. Hoy dia reside en Venezuela, y ejerce la profisión de arquiteto, pero 
ha tenido tiempo para recordar a su provincia natal y derramar sus emociones y sentimientos en una lírica llena de elementos sociales, pero expressados muy poéticamente. El se une en espiritu con el pueblo en general, y una vez que logra solidarizarse en sus versos, comunica la idea universal de que el hombre esta vinculado no sólo a la fuerza del progresso, sino al destino que sirve de denominador común a toda la humanidad.

En 1951, nació la más conocida de las poetisas actuales, Margarita Ledo Andion. Ella es natural de Castro de Rey. Entre su producción más conocida se encuentram los libros: Parolar cun eu, cun intre, cun inseuto yO corvo erguese cedo. Para ella es importante identificarse con la provincia gallega. Tanto la mar, como la tierra, la fábrica, las casas, en fin todo lo físico que se encuentre en la patria chica. Su objeto principal es comprometerse de lleno con lo que forma una parte del todo, y de esa forma llegar a formar una fusión absoluta con lo que pueda representar a la provincia. Junto a ella se debe estudiar al joven Darío Xoan Cabaña, nacido en Roas, Lugo, en 1952. A pesar de ser tan joven, su producción es bastante, siendo sus principales publicaciones: Verbas a un irmão, Home e terra, y Noticia dunha aldea. Su posición en la vida es de actitud crítica, sobre todo en relación a la época en la cual le ha correspondido vivir. Su dominio del verso y su conocimiento de la lengua es algo extraordinario. La poesía que ha producido es honesta y firme, directa y llena de sabiduria que no pertence a un hombre de tan pocos años. El piensa que la poesía es esencial en la cultura del hombre, y que influye enormemente en el quehacer histórico. Tambiém reafirma que la lírica es un arte por sí, de ahi que deba poseer un alto valor estético.

Finalmente, se debe incluir al gran poeta gallego que es considerado como el jefe silencioso de esta nueva legión de escritores. Este admirable y único poeta es Celso Emilio Ferreiro. Aunque nacido en 1914, su espíritu es tan joven como el más joven de los poetas gallegos de la actualidad. Celso Emilio se creó dentro de un ambiente adverso a la poesía regionalista, y dentro de una esfera donde la lengua materna estaba principalmente en manos de ciudadanos incultos que no sabian ni leer ni escribir. La poesía que sobrevive estos años de lucha tiene dos vertientes bien delineadas; una que se funde en el llanto y el perenne sufrimiento gallego, y la otra que se encauza hacia la constante emigración de esa sufrida provincia española.

En medio de este ambiente comienza Celso Emilio Ferreiro a resaltar como uno de los mejores exponentes de la poesía gallega. el tuvo una buena instrucción en su villa natal de Celanova (Orense). Allí había nacido Curros Enriquez, el gran poeta gallego del siglo diecinueve, el apasionado defensor de la libertad. Tal es la unión que Celso Emilio siente con Curros, que en 1954, publicó la mejor biografía del mal entendido poeta celanovense. Trabajo que hoy dia esta revisando para una nueva edición. Esta obra apareció en una fecha clave, pues estos fueron los años que impulsaron la renaudación de la larga tradición lírica en la provincia. Esta obra empujó a numerosos neófitos de la poesía gallega, los cuales sirvieron de puente con el siglo anterior.

Contrario a lo que dicen los críticos, el primer libro de Celso Emilio no surgió en 1935, ya que Cartafol no fue un libro, sino un folio de cartas que contenía un número de poemas sueltos, que un grupilho de poetas adolescentes circulaban entre ellos durante los años treinta. Este patriarca de la poesia gallega que hoy día es presidente del Ateneo de Madrid, sacó al mundo por primeira vez varios trabajos por los años cuarenta, pero en la lengua castellana. Esto 
fue a causa de la gran represion que existia en España contra toda forma de expresión que tuviese eco de separatismo. Por el año 1954 surge en Pontevedra un libro de poemas, O sono sulagado, publicación que le pone rapidamente al frente de la poesia gallega actual. En ese libro el autor logra encontrarse de nuevo después de los largos años de desconcierto que fueron el pruducto de la contienda del 36 . El poeta toma de nuevo dl dominio de su destino, y le hace frente a la triste y horrible realidad del momento. Se deshace de la posicion individualista que había regido su ser, y se funde espiritualmente con el resto de la humanidad. Surge como como representante máximo del ser humano y los problemas que acosan a éste diariamente, no sin dejar de expresar la dolorosa pespectiva que percibe a través del mundo que le circunda.

Celso Emilio es un escritor que florece cuando es cuarentón, pero su mejor poesía es aun más tardía, ya que Longa noite de pedra, para muchos su mejor obra, y una de las mejores dentro de la literatura galllega, aparece en 1962. Este trabajo le coloca indirectamente como maestro de los poetas jóvens que se han mencionado anteriormente.

El señor Ferreiro ha logrado renovar la poesía gallega al darle un aire juvenil donde se inhala la expontaneidad y se revaloriza el prosaismo que tanto había sido atacado por sus precesores. La imagen en su lírica es puramente funcional. Es decir, que la imagen es un fin en sí misma y está en funcion del conjunto del poema. La obra celsiana permea un efecto en especial, y refuerza un número de aspectos que el escritor quiere comunicar al lector. Sus versos están llenos de ironía, y esto le sirve como mecanismo de defensa, y no como encauzamiento de ideas violentas al intercalarse éstos con su poesía de intención colectiva. En su lenguaje se puede apreciar la gran contribución que Celso Emilio ofrece a la lírica galaica. Ya que la lengua tiene una gran libertad gramatical y léxica, el poeta puede emerger como creador y contribuyente al idioma. Pero en este campo de libre experimentación linguística, el escritor tropíeza con un pueblo que conserva la lengua con una fidelidad instintiva, bajo la opresión de la lengua oficial. El poeta busca y rebusca en la lengua rural, la proletaria, la oral, la viva, la que esta repleta de aracaismo u lusismos, y le de poca consesión a la literaria. Su lenguaje, aunque cuidado y pulido, encuentra su basé en el pueblo, y ayuda a preservar la herencia que por tantos siglos ha pasado de generación a generación. Estás son las cualidades del escritor que hacen que muchos críticos le consideren como el mejor poeta después de Rosália de Castro. El es un autor auténtico, hombre de carne y hueso que ha pasado y sufrido muchas de las dificultades y vejaciones por las condujo a la emigración. Aunque el régimen franquista no le echó del país, él se vió impulsado al éxodo, ya que al igual que miles autodestierro fue más espiritual que físico, y utilizó esta experiencia para crear una obra literaria que perdurará con los siglos. Su poesía aunque a veces peca de intimista, le coloca dentro de un marco que se desborda con realidades colectivas. Así pues, cuando Celso Emilio Ferreiro hace referencia a su "yon, se ve la nota problemática que ataca a toda una comunidad gallega. Su bella lírica puede apreciare en un hermoso poema donde el escritor expresa su joven espiritu dentro de un marco poético que rebosa en unos versos a la vez modernos y tradicionalistas, Pra Mocedade: 
aos profesores de mitos, que queren de contrabando pasar falsos paradisos.

Non, non diredes arreo aos que van no seu machiño cabalgando moi contentos entre nubes de outimismo.

Non, non debedes decir aos que minten por oficio. A verda, soio a verda da terra na que vivimos, labrada en berros de lume, nascida en berce cativo.

A verda, soio a verda da terra que nascimos». (3)

Como se puede apreciar la poesía dela posguerra implica un nuevo concepto de la problemática y del lenguaje, pero conserva en su totalidad las raí-c ces de la anterior. Esto se debe a que la realidad que le sirve de inspiración. contiene los mismos elementos que afectaron a los escritores de la época anterior. El medio ambiente es el mismo y por lo tanto no existe una diferencia abismal entre la poesía actual y la tradicional, que principalmente se identifica con la tierra y el futuro. La preocupación de la lírica gallega actual no es estar al dia de las corrientes europeas y americanas que surgen en la actualidad, sino que se esmera en tratar de meterse de lleno en lo histórico, lo social y especialmente lo linguístico de la provincia gallega. Galicia al igual que otras provincias españolas sigue manteniendo su espíritu individualista que ha logrado sobrevivir, al menos a través de su poesía nova.

East Tennessee State University

Johnson City, Tennessee 37601 U.S.A.

\section{NOTAS}

1. Marcelino Menéndez Pelayo, Obras completas, vol. I, (Madrid: Consejo Superior de Investigadores Científicas, 1941), págs. 160-161. pág. 13.

2. Marqués de Santillana, Proemio al condestable de Portugal (Madrid: BAE, 1965),

3. Celso Emilio Ferreiro, Obra completa, vol. I, (Madrid: AKAL Editor, 1975), pág. 318. 